\title{
Bilateral aberrant internal carotid arteries discovered during myringotomy: A case report and review of the literature
}

\author{
Marc Antoine Hudon*1, Margaret Aron ${ }^{2}$, Mireille Gervais ${ }^{1}$ \\ ${ }^{1}$ Otolaryngology, Université de Sherbrooke (CHUS), Canada \\ ${ }^{2}$ Hôpital du Haut-Richelieu, Canada
}

\author{
Received: May 15, 2018 \\ Accepted: May 25, 2018 \\ Online Published: May 28, 2018 \\ DOI: $10.5430 /$ css.v4n1p23 \\ URL: https://doi.org/10.5430/css.v4n1p23
}

\begin{abstract}
The aberrant course of the intratympanic carotid artery is a rare congenital vascular anomaly. We report the case of a 7-year-old patient who presented with bilateral conductive hearing loss, originally attributed to otitis media with effusion. After myringotomy, massive pulsatile bleeding occurred on the right side. The bleeding was successfully controlled with packing without any residual complication. Imaging confirmed aberrant internal carotid arteries abutting the tympanic membranes bilaterally.
\end{abstract}

Key Words: Aberrant internal carotid artery, Conductive hearing loss, Myringotomy

\section{INTRODUCTION}

An aberrant internal carotid artery (ICA) is thought to result from the failure to develop or abnormal involution of the cervical portion of the ICA and the subsequent enlargement and anastomosis of the usual small vessels of the middle ear (caroticotympanic and inferior tympanic arteries). ${ }^{[1-3]}$ An aberrant carotid artery enters the middle ear through an enlarged inferior tympanic canal and courses across the middle ear from posterior-inferior to anterio-superior in order to join the petrous ICA. ${ }^{[1,3]}$ In its course through the middle ear, an aberrant ICA may be asymptomatic or can cause pulsatile tinnitus and, although not universal, conductive hearing loss if abutting the tympanic membrane or ossicles. ${ }^{[2]}$

\section{CASe PResentation}

A 7-year-old girl, otherwise healthy, was scheduled for bilateral tympanostomy tubes and adenoidectomy at the Cen- tre Hospitalier Universitaire de Sherbrooke (CIUSS-EstrieCHUS). She had persistent bilateral opacified middle ears on physical exam with conductive hearing loss and flat tympanograms (type B) on two different audiograms in 2012 and 2013. A history of recurrent acute otitis media was also reported. All findings supported a diagnosis of persistent bilateral chronic otitis media with effusion and consent for myringotomy and tube placement was obtained.

Microscopic otoscopy under general anaesthesia in the operating room, showed bilateral hyper-vascular non-pulsatile tympanic membranes compatible with the pre-operative diagnosis. On the left side, an antero-inferior myringotomy was completed, through a slight amount of mucoid fluid was suctioned and a tympanostomy tube inserted. On the right side, however, myringotomy in the antero-inferior quadrant resulted in sudden excessive bleeding which rapidly filled the external auditory canal (EAC). When adrenaline-soaked

\footnotetext{
*Correspondence: Marc Antoine Hudon; Email: marc.antoine.hudon@usherbrooke.ca; Address: 580 Rue Bowen S, Sherbrooke, QC J1G 2E8, Canada.
}

Published by Sciedu Press 
cotton packing did not stop the bleeding, a significant vas- The angioCT was consistent with aberrant ICAs bilaterally. cular anomaly was suspected. The EAC was tightly packed with ribbon gauze and the patient was urgently transferred to the radiology department for an angiovascular computed tomography (angioCT).

A thin layer of bone surrounded the aberrant ICA on the left side, but was absent over at least $2 \mathrm{~mm}$ on the right (see Figure 1).

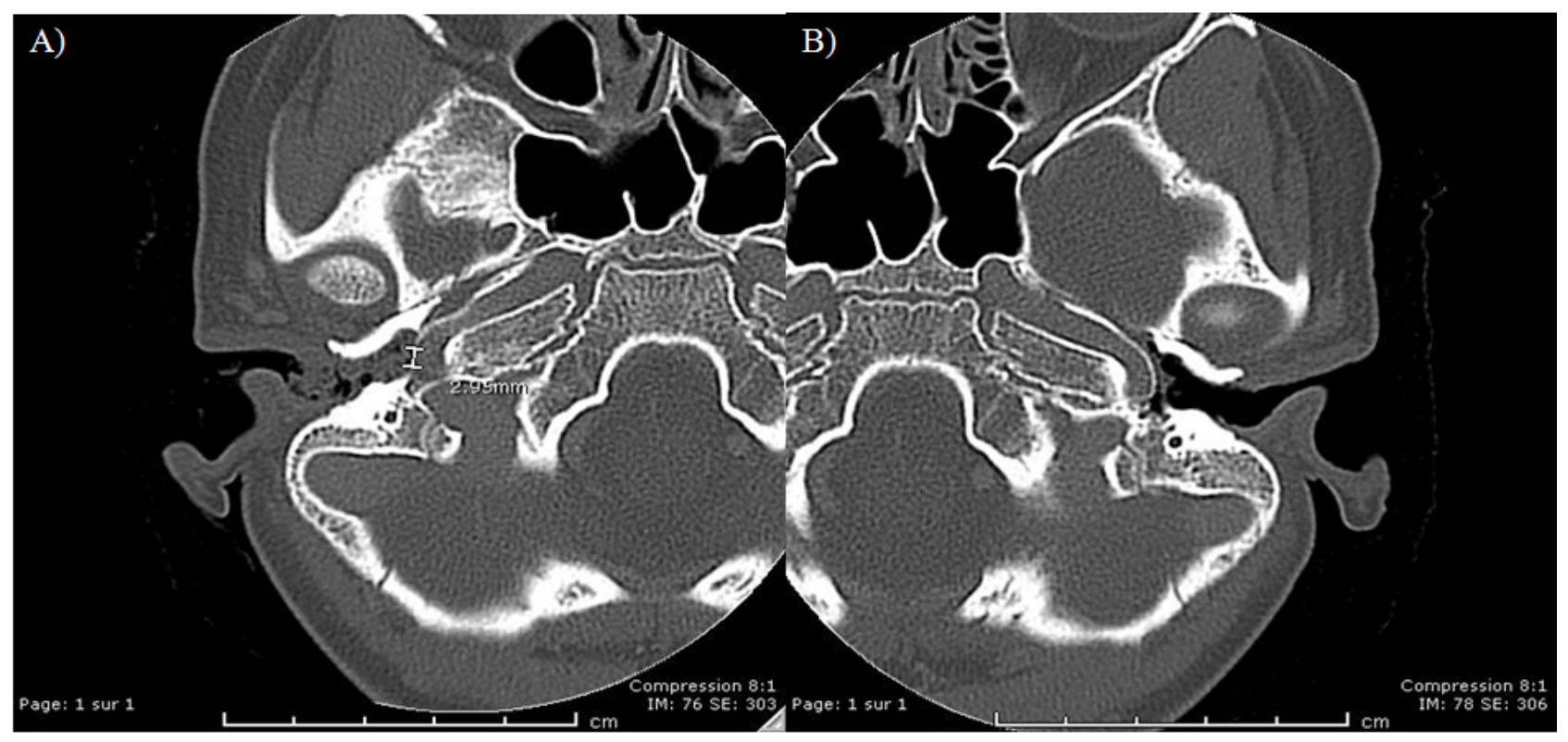

Figure 1. High resolution angioCT centered on the mastoids. A) Axial view aberrant carotid on the right side lacking bony coverage over at least $2 \mathrm{~mm}$; B) Axial view showing aberrant carotid on the left side with good bony coverage (arrow)

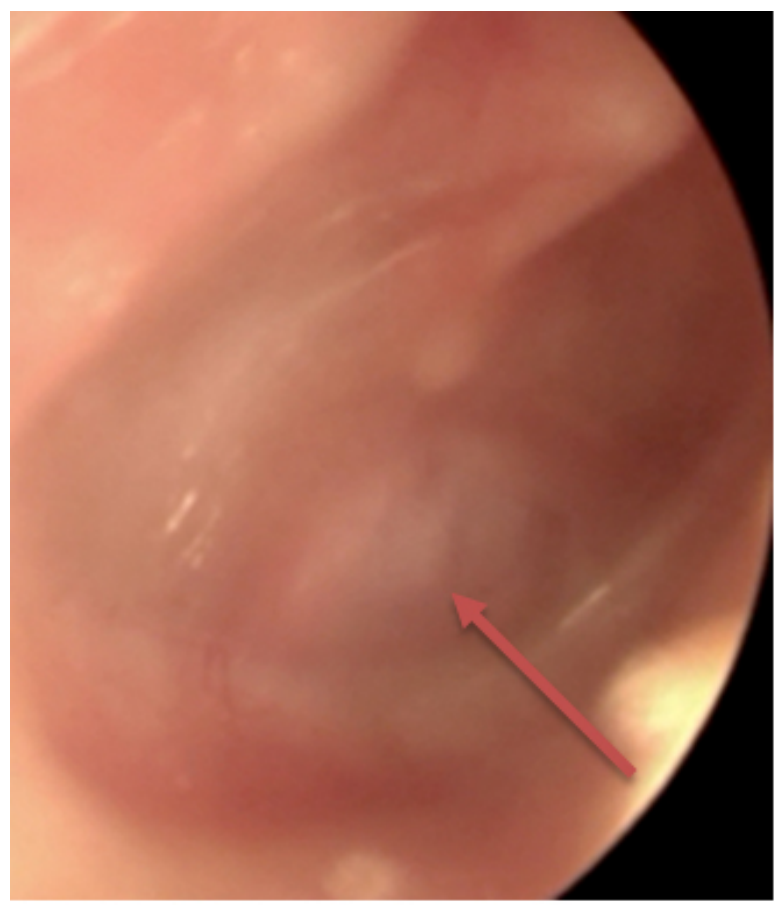

Figure 2. Right tympanic membrane view by endoscopy at 5 months showing retrotympanic pulsatile mass (arrow)

The patient was admitted to the pediatric ward for bleeding and neurologic surveillance. Given the absence of active otorrhagia or neurologic symptoms during her stay, she was discharged home after 1 week.

Two weeks post-operatively, her ear was successfully unpacked under general anaesthesia and there was no recurrent bleeding.

AngioMRI confirmed the absence of dissection or pseudoaneurysm of the right ICA.

At the 5-month post-operative follow-up appointment, microscopic otoscopy showed a healed tympanic membrane on the right side with a visible pulsatile retrotympanic mass (see Figure 2). The audiogram revealed the persistence of a significant air-bone gap bilaterally with a type B tympanogram (see Figure 3). There was no improvement in her hearing.

\section{DiscuSSION}

Being congenital in most cases, aberrant ICA can present at any age.$^{[4,5]}$ It mostly occurs to females and are unilaterally on the right side. ${ }^{[5,6]}$ Although no clear etiology has been found for this anomaly, an embryogenic malformation of the first and second branchial arches has been proposed as a plausible cause. ${ }^{[7]}$ The clinical diagnosis of aberrant ICA is difficult given the frequent absence of specific signs or 
symptoms ${ }^{[3,7]}$ particularly in young children who may not be able to describe possible pulsatile tinnitus. In addition to presenting as pulsatile tinnitus, an aberrant ICA can present with conductive hearing loss, as a pulsatile retrotympanic mass on physical exam, ${ }^{[2,3,7]}$ or as in our case, unexpectedly during middle ear surgery due to a middle ear effusion mak- ing pre-operative diagnosis of ICA based on symptoms and physical exam difficult. When suspected, the diagnosis can be confirmed with a high-resolution CT scan. ${ }^{[3,7]}$ Once identified, if surgery is still necessary (recurrent otitis or otitis media with effusion and hearing loss) it should be performed with utmost care. ${ }^{[2]}$

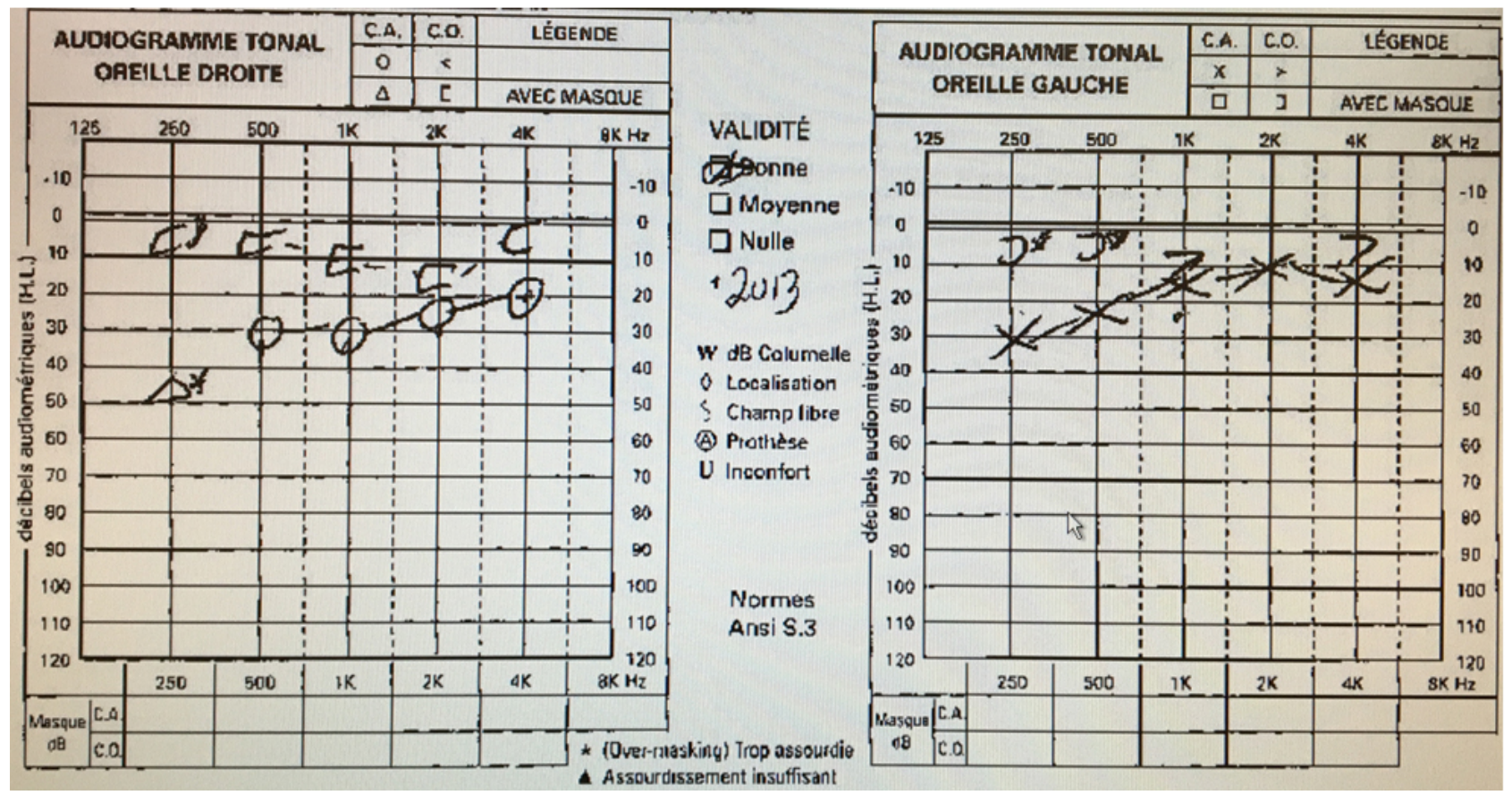

Figure 3. Persistence of a bilateral conductive hearing loss on the post-operative audiogram

The literature contains fifty-seven cases of aberrant ICAs reported between 1972 and 2012. ${ }^{[3]}$ At least nine cases presented with otorrhagia during middle ear surgery. ${ }^{[3]}$ Reported management strategies include ear packing for variable (or unspecified) durations, surgical ICA obliteration and angiovascular occlusion. The variable management strategies and outcomes reported speak to the lack of a consensus on the optimal treatment to assure bleeding control and avoid vascular complications in these cases. For example, in a case reported by Knox et al. significant hemorrhage which was managed by surgical occlusion of the aberrant portion of the ICA in the temporal bone. The patient did not develop neurologic deficits, presumably due to good collateral circulation. Although the use of initial packing in this case was not specified, the ear was reportedly packed upon recurrence of bleeding but the duration of packing was not reported. ${ }^{[1]}$ Takano et al. reported on a case where the bleeding ear was packed but only until cessation of otorrhagia in the operating room. A pseudoaneurysm was detected thereafter, the surgical treatment of which resulted in a cerebral infarction of $70 \%-80 \%$ of her cerebral hemisphere. ${ }^{[8]}$ Sauvaget et al. encountered four cases of aberrant ICA during myringotomy.
Two of these resolved with packing, while the other two required additional interventions due to persistent bleeding despite packing. ${ }^{[9]}$ The duration of packing was not specified in these cases. ${ }^{[9]}$ In our case, otorrhagia was controlled in the operating room with ear packing and did not recur after unpacking two weeks later. Hunt et al. describe a similar case which resolved with only one week of packing, ${ }^{[10]}$ suggesting that one week may have been sufficient in our case as well. Equally as importantly, our patient did not have any vascular complications such as pseudoaneurysm or stroke after the incident. Although we cannot know exactly why our case responded to conservative management in the way of packing alone and did not have any vascular complications, we presume it is because the initial traumatic injury to the ICA was minimal as the gesture was aborted immediately upon evidence of otorrhagia, probably minimizing the extent of vascular injury.

Based on our experience from this case and a review of the literature, it is clear that although the pre-operative diagnosis of aberrant ICA can be difficult to make, particularly in the case of concomitant otologic pathology such as middle 
ear effusion, initial myringotomy should be made cautiously and as minimally as necessary in all cases and, if severe otorrhagia is encountered and found to be due to injury of an aberrant ICA, ear packing for at least 1 week can be an effective and safe treatment strategy.

\section{Conclusions}

An aberrant ICA is a rare vascular anomaly which can rarely present as unexpected massive otorrhagia during myringotomy. In such cases tight ear packing left in place for 1-2 weeks can be considered as an effective, safe and conservative treatment strategy.

\section{ACKNOWLEDGEMENTS}

We thank Dre Nadia Hagenimana for her help with the writing of the case report.

\section{Consent}

Written informed consent was obtained from the patient and legal tutors for the publication of this report and any accompanying images.

\section{Conflicts of InTEREST Disclosure}

The authors declare they have no conflicts of interest.

\section{REFERENCES}

[1] Knox WJ, Milburn JM, Dawson R. Bilateral aberrant internal carotid arteries: treatment of a hemorrhagic complication. Am J Otolaryngol. 2007; 28(3): 212-217. PMid: 17499144. https://doi.org/10.1 016/j.amjoto.2006.07.014

[2] Yetişer S. Aberrant carotid artery in the middle ear. Balkan Med J. 2015; 32(1): 111-113. PMid: 25759782. https://doi.org/10.5 152/balkanmedj . 2015. 15268

[3] Song YS, Yuan YY, Wang GJ, et al. Aberrant internal carotid artery causing objective pulsatile tinnitus and conductive hearing loss. Acta oto-laryngologica. 2012; 132(10): 1126-30. PMid: 22779753. https://doi.org/10.3109/00016489.2012.684400

[4] Jacobsson M, Davidsson A, Hugosson S, et al. Aberrant intratympanic internal carotid artery. A potentially hazardous anomaly. J Laryngol Otol. 1989; 103: 1202-5. PMid: 2614241. https://doi. org/10.1017/S002221510011134X

[5] Ridder GJ, Fradis M, Schipper J. Aberrant internal carotid artery in the middle ear. Ann Otol Rhinol Laryngol. 2001; 9: 892-4. PMid: 11558768. https ://doi.org/10.1177/000348940111000915
[6] Sinnreich AI, Parisier SC, Cohen NL, et al. Arterial malformations of the middle ear. Otolaryngol Head Neck Surg. 1984; 92: 194-206. PMid: 6425774. https://doi.org/10.1177/01945998840920 0212

[7] Tugrul S, Eren SB, Dogan R, et al. Intratympanic aberrant and hypoplastic carotid artery. Am J Otolaryngol. 2013; 34(5): 608-610. https ://doi.org/10.1016/j.amjoto.2013.02.010

[8] Takano K, Wanibuchi M, Ito F, et al. Pseudoaneurysm of an aberrant internal carotid artery in the middle ear caused by myringotomy. Auris Nasus Larynx. 2016; 43(6): 698-701. PMid: 27085819 https ://doi.org/10.1016/j.anl.2016.03.010

[9] Sauvaget E, Paris J, Kici S, et al. Aberrant internal carotid artery in the temporal bone: imaging findings and management. Arch Otolaryngol Head Neck Surg. 2006; 1: 86-91. PMid: 16415436. https://doi.org/10.1001/archotol.132.1.86

[10] Hunt JT, Andrews TM. Management of aberrant internal carotid artery injuries in children. Am J Otolaryngol. 2000; 1: 50-4. https : //doi.org/10.1016/S0196-0709(00)80125-8 